$17^{\circ}$ ERGODESIGN

\& USIHC 2019

PUC-Rio, 11 a 13 de dezembro

Rio de Janeiro, RJ, Brasil $17^{\circ}$ Ergodesign - Congresso Internacional de Ergonomia e Usabilidade de Interfaces Humano Tecnológica: Produto, Informações Ambientes Construídos e Transporte

$17^{\circ}$ USIHC - Congresso Internacional de Ergonomia e Usabilidade

de Interfaces Humano Computador

\title{
Barreiras no uso de assistentes de voz por usuários brasileiros de smartphone
}

\author{
Issues in the use of voice assistants by Brazilian smartphone users
}

\author{
MOTTA, Isabela \\ LEUI | Laboratório de Ergodesign e Usabilidade de Interfaces da PUC-Rio, Graduanda em \\ Design pela PUC-Rio \\ isabela.canellas@gmail.com
}

\author{
QUARESMA, Manuela \\ LEUI | Laboratório de Ergodesign e Usabilidade de Interfaces da PUC-Rio, Doutora em Design \\ pela PUC-Rio \\ mquaresma@puc-rio.br
}

\section{RESUMO}

O uso de smartphones no Brasil é crescente, assim como o número de tarefas realizadas por meio desse dispositivo. Considerando isso, é necessário pensar outras formas de interação dos usuários com 0 smartphone, além da interface visual. Assim, os assistentes de voz - agentes de inteligência artificial que realizam diversas tarefas por meio da voz - se apresentam como uma alternativa que traz benefícios para a interação. Apesar de suas vantagens, ainda existem barreiras que impactam o uso desses sistemas pelos usuários de smartphone. Este artigo apresenta parte dos resultados de um questionário online com usuários brasileiros de smartphone, que teve como objetivo entender quais são as principais características dos assistentes de voz que impactam negativamente o seu uso. Os resultados mostraram que questões de atitude são as principais barreiras para o uso dos assistentes, como o desconforto em falar com o assistente em público e o costume com a interface visual. Além disso, foi observado que 0 desconhecimento sobre o assistente pode ser um motivo que leva os usuários a não usarem a voz.

Assistentes de voz, interação por voz, smartphones, barreiras no uso de tecnologias;

\section{ABSTRACT}

The use of smartphones in Brazil is increasing, and so is the number of tasks that can be accomplished by this device. Considering this, thinking other means of user interaction to smartphones besides the visual interface is in order. Thus, voice assistants - virtual agents that use artificial intelligence to perform tasks by voice interaction - are an alternative that brings several benefits. However, despite its advantages, that are still issues in the use of those systems that impact its use by smartphone users. This paper presents part of the results of an online questionnaire with Brazilian smartphone users, which aimed to understand what characteristics of voice assistants negatively impacts its use. The results showed that problems related to attitude are the main issues impacting the use of the assistants, such as the discomfort in talking to the assistant in public and the habit of using visual interfaces. Moreover, it was 


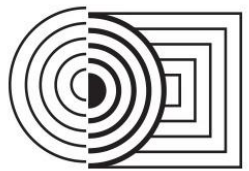

\section{$17^{\circ}$ ERGODESIGN \& USIHC 2019 \\ PUC-Rio, 11 a 13 de dezembro \\ Rio de Janeiro, RJ, Brasil}

$17^{\circ}$ Ergodesign - Congresso Internacional de Ergonomia e Usabilidade de Interfaces Humano Tecnológica: Produto, Informações Ambientes Construídos e Transporte

$17^{\circ}$ USIHC - Congresso Internacional de Ergonomia e Usabilidade

de Interfaces Humano Computador

also observed that the lack of knowledge about the assistant itself may be a reason for smartphone users not to use the voice interaction.

Voice assistants, voice interaction, smartphones, issues in technology use;

\section{INTRODUÇÃO}

O número de usuários de smartphones no Brasil é crescente. Segundo o Google Consumer Barometer (GOOGLE, 2017), 67\% dos brasileiros usavam smartphones em 2017. Atualmente, com a evolução da tecnologia de hardware e software, cada vez mais tarefas podem ser desempenhadas pelo smartphone. Esse aumento das possibilidades em termos de atividades em smartphones significa, também, a necessidade de pensar diferentes tipos de interação, flexíveis para as mais diversas implementações e adequados às necessidades dos usuários. Nesse cenário, a interação por meio de assistentes de voz é uma alternativa que vem evoluindo e ganhando cada vez mais espaço e popularidade.

Os assistentes de voz, como a Siri e a Alexa, são assistentes virtuais - agentes de inteligência artificial que realizam diversas tarefas em um sistema - com os quais os usuários podem interagir por meio de uma interface de voz, acompanhada ou não de uma interface visual (WEST, KRAUT, CHEW, 2019). Esses assistentes de voz podem operar em diferentes dispositivos, como em smartphones, fones de ouvido e caixas de som inteligentes dedicadas a eles, os smart speakers. O uso dos produtos com essas interfaces é cada vez mais popular entre os usuários. Segundo a Google, $50 \%$ das buscas serão feitas por voz até 2021 (GOOGLE, apud INVOCA, 2018), e, até o mesmo ano, o número de assistentes de voz ultrapassará o número de pessoas no planeta (WEST et al., 2019).

Os assistentes de voz oferecem uma série de benefícios para os usuários. Segundo a West et al. (2019), a interação com os assistentes de voz busca requerer o mínimo esforço de uso pelo usuário. Além disso, os assistentes também não exigem que o usuário esteja fisicamente perto o suficiente para enxergar informações visuais (AMAZON, 2019). Outro benefício dos assistentes de voz é sua intuitividade, uma vez que usam a fala, uma linguagem natural aos seres humanos (AMAZON, 2019; PEARL, 2016, KLEINER PERKINS, 2016). Ainda, os assistentes de voz têm grande potencial para a acessibilidade.

Apesar dos benefícios dos assistentes de voz, é possível perceber diversas questões na interação por voz que podem contribuir para uma menor adesão à essas interfaces. Uma das desvantagens das interfaces de voz é a privacidade. Diferente do canal visual, não é possível controlar (a menos que por fones de ouvido) a propagação do som e quem estará ouvindo os comandos do usuário ou as respostas do sistema. Além disso, apesar dos avanços na tecnologia de captação de voz, problemas de reconhecimento e interpretação dos comandos ainda acontecem nas interfaces de voz, o que afeta o desempenho do sistema (QUARESMA, MOTTA e ARAUJO, 2018).

Considerando esses problemas, é previsível que as desvantagens da interação por voz impactem, de alguma forma, a experiência dos usuários com os assistentes de voz e sua adesão a esse tipo de interface. No entanto, ainda não se sabe como e o quanto essas questões afetam o uso real de assistentes de voz por usuários de smartphone. Este artigo expõe parte dos resultados de uma pesquisa com usuários, com o objetivo de avaliar se, e quais, características dos assistentes de voz impactam negativamente o uso desses assistentes pelos usuários de smartphone, e a que nível isso acontece. 


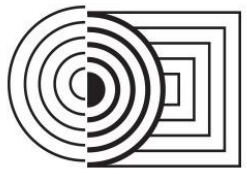

$17^{\circ}$ ERGODESIGN \& USIHC 2019

PUC-Rio, 11 a 13 de dezembro

Rio de Janeiro, RJ, Brasil $17^{\circ}$ Ergodesign - Congresso Internacional de Ergonomia e Usabilidade de Interfaces Humano Tecnológica: Produto, Informações Ambientes Construídos e Transporte

$17^{\circ}$ USIHC - Congresso Internacional de Ergonomia e Usabilidade de Interfaces Humano Computador

\section{BARREIRAS NO USO DE ASSISTENTES DE VOZ}

Diversos fatores podem afetar a aceitação de sistemas e a experiência dos usuários, e a literatura aponta algumas dimensões que podem impactar o uso de assistentes de voz. Em primeiro lugar, a percepção de utilidade é uma dimensão influente no uso de sistemas de informação. Davis (1989) define percepção de utilidade como "o grau que uma pessoa acredita que usar um determinado sistema melhoraria o desempenho de seu trabalho". (DAVIS, 1989, p. 2, tradução nossa). Foi observado, na literatura, que a percepção de utilidade afeta o uso de assistentes de voz. McLean e Osei-Frimpong (2019) realizaram um questionário online sobre 0 uso da Alexa no Amazon Echo. Os resultados do estudo mostraram um efeito significativo dos benefícios utilitários no uso dos assistentes de voz. Essa tendência também pode ser observada em levantamentos realizados em publicações do mercado. Uma pesquisa realizada pela comScore (2017b) levantou os principais motivos para os americanos não usarem um smart speaker com assistente de voz. Os resultados mostraram que $40 \%$ dos respondentes afirmaram que o smart speaker "Não é relevante" e, $23 \%$, que "Não é muito útil".

Outra dimensão identificada como influente no uso dos assistentes de voz é a percepção de usabilidade, que "(...) se refere ao grau que uma pessoa acredita que o uso de um determinado sistema seria livre de esforço" (DAVIS, 1989, p. 2, tradução nossa). O estudo realizado por Moriuchi (2019) mostrou uma relação significativa entre a percepção de usabilidade e o uso de assistentes de voz. Em linha com essa possibilidade, um estudo feito pela Invoca (2018) mostrou que quase metade dos participantes do estudo alegou que os assistentes de voz falham em reconhecer seus comandos em pelo menos um quarto do tempo de uso. De forma similar, o estudo realizado por Maués (2019) mostrou, por meio de grupos de foco com usuários de assistentes virtuais personificados, que os participantes tinham uma forte percepção de que os assistentes têm problemas em interpretar e executar seus comandos, inclusive, os comandos que misturam palavras em mais de um idioma.

Além das percepções de utilidade e usabilidade, outro fator influente no uso de assistentes de voz é a atitude em relação ao uso desses sistemas. Osgood (1957) define atitude como "um processo implícito aprendido (...) que pode ser referido como 'tendências de aproximação ou rejeição' ou 'favorabilidade ou não-favorabilidade'" (OSGOOD, 1957, p. 189, tradução nossa). Indícios de que a atitude influencia no uso da interação por voz foram encontrados por Moriuchi (2019), que identificou impacto significativo dessa dimensão no uso de assistentes de voz. Em linha com esses resultados, o levantamento feito pela comScore (2017b) mostrou que $24 \%$ dos respondentes apontaram o fato de ser "Desconfortável falar com um dispositivo" como um motivo para não usar smart speakers. De forma similar, outro estudo realizado pelo Reuters Institute (2018) identificou que falar com um dispositivo foi considerado não natural pelos usuários (REUTERS INSTITUTE, 2018). Além disso, a pesquisa realizada por Maués (2019) mostrou que uma grande barreira no uso de assistentes de voz apontada por usuários foi o desconforto em falar com o assistente em público.

Mais um fator identificado na literatura como barreira para o uso de assistentes de voz foi a percepção de um risco de privacidade das informações coletadas pelos assistentes. $O$ impacto dessa dimensão foi demonstrado por McLean e Osei-Frimpong (2019), que identificaram os riscos de privacidade como fator moderador no uso de assistentes de voz. Essa tendência é reafirmada no estudo realizado pelo Reuters Institute (2018) que demonstrou que, dentre os motivos citados para não usar os assistentes de voz, estão questões de privacidade e preocupação com grandes empresas estarem ouvindo as conversas dos usuários em casa.

Finalmente, é possível que os usuários possuam um modelo mental de funcionamento dos assistentes de voz, que pode influenciar o uso desses sistemas. Segundo 


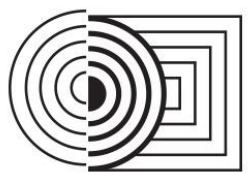

\section{$17^{\circ}$ ERGODESIGN \& USIHC 2019 \\ PUC-Rio, 11 a 13 de dezembro \\ Rio de Janeiro, RJ, Brasil}

$17^{\circ}$ Ergodesign - Congresso Internacional de Ergonomia e Usabilidade

de Interfaces Humano Tecnológica: Produto, Informações Ambientes Construídos e Transporte

$17^{\circ}$ USIHC - Congresso Internacional de Ergonomia e Usabilidade

de Interfaces Humano Computador

Nass \& Moon (2000), os seres humanos costumam traduzir certas regras de interação humanohumano para a interação humano-computador de forma inconsciente. Percepção de gênero e as construções sociais aplicadas a gênero foram observadas na interação de usuários com computadores que usavam respostas por voz (NASS e MOON, 2000). De forma similar, Nass \& Brave (2005) demonstraram que os usuários de computadores tendem a ter uma relação de cooperatividade e culpabilidade com máquinas para realizar uma determinada tarefa. Dessa forma, considerando que os assistentes de voz apresentam características que imitam traços humanas, como a fala e personalidade, e que os humanos tendem a traduzir suas tendências de comunicação na interação com máquinas, é possível argumentar que os usuários tenham um modelo mental de funcionamento desses assistentes, e que esse modelo mental pode afetar a forma com que interagem.

A literatura aponta para as principais barreiras no uso de assistentes de voz. No entanto, é possível observar que grande parte dos estudos existentes sobre o assunto foram realizadas com usuários fora do Brasil. Além disso, as publicações coletadas tratam de assistentes de voz sem fazer distinção de dispositivos, e não apenas em smartphones, que têm especificidades como um aparato visual de apoio, por exemplo. Dessa forma, é possível observar a necessidade de um levantamento com uma grande amostra de usuários brasileiros de smartphone para identificar as principais barreiras de uso dos assistentes de voz para esses usuários de smartphone.

\section{MÉTODO}

Com o objetivo de levantar dados sobre o uso e a experiência de usuários brasileiros de smartphone com assistentes de voz, foi elaborado um questionário online na plataforma Eval\&Go (Eval\&Go, 2019). Neste artigo, será reportada parte dos resultados do questionário, referentes às respostas dos usuários de smartphone que afirmaram ter frequência de uso de assistentes de voz esporádica (poucas vezes ao ano) e dos que afirmaram não usar os assistentes. Assim, os resultados irão apresentar as barreiras e motivos que levam esses participantes a não utilizar assistentes de voz em sua rotina.

O questionário online foi divulgado por meio de redes sociais para os participantes. $\mathrm{O}$ modelo remoto foi escolhido porque permite o recebimento de uma grande quantidade de respostas. Os requisitos de participação para responder ao questionário eram ser maior de 21 anos e usuário de smartphone, independente do uso de assistentes de voz, ou não. O tempo de completude do questionário foi de cerca de cinco a sete minutos, e as perguntas foram divididas em algumas seções: 1) Introdução; 2) Uso de assistentes de voz; 3) Motivos para não usar assistentes de voz e; 4) Perfil demográfico.

$\mathrm{Na}$ introdução, os participantes eram apresentados à pesquisa e ao propósito do questionário, e deveriam concordar em participar da pesquisa. Na próxima seção, os participantes responderam perguntas básicas sobre uso de assistentes de voz: "Você usa assistentes de voz? "; "Você tem assistentes de voz em algum dispositivo? "; "Quais dispositivos você tem? ". Os participantes que afirmaram não ter assistentes de voz eram redirecionados para a pergunta "Qual é a marca e modelo do seu smartphone? ". Essa pergunta serviu para averiguar se os usuários realmente sabem se têm assistentes de voz, ou não. Os demais participantes eram redirecionados para a seção de "Motivos para não usar assistentes de voz".

Para avaliar quais características dos assistentes de voz se apresentavam como barreiras de uso para usuários de smartphone, foram desenvolvidas algumas escalas de avaliação. As escalas começaram com a afirmação "Eu deixo de usar os assistentes de voz porque:__ seguida de uma série de frases complementares, apresentadas em escalas 


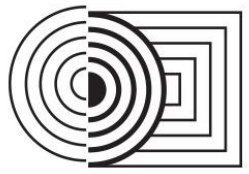

\section{$17^{\circ}$ ERGODESIGN \& USIHC 2019 \\ PUC-Rio, 11 a 13 de dezembro \\ Rio de Janeiro, RJ, Brasil}

$17^{\circ}$ Ergodesign - Congresso Internacional de Ergonomia e Usabilidade de Interfaces Humano Tecnológica: Produto, Informações Ambientes Construídos e Transporte

$17^{\circ}$ USIHC - Congresso Internacional de Ergonomia e Usabilidade de Interfaces Humano Computador

Likert de 5 pontos, que variavam de "Concordo plenamente" a "Discordo plenamente". As escalas (quadro 1) foram desenvolvidas a partir das barreiras de uso de assistentes de voz encontradas na literatura e de entrevistas prévias realizadas com usuários de interfaces de voz, considerando as dimensões influentes no uso de assistentes de voz (coluna da esquerda no quadro 1) e as características específicas da interação por voz. A escala relativa aos riscos de privacidade foi adaptada de McLean e Osei-Frimpong (2019). Por fim, depois de responderem algumas perguntas sobre seu perfil demográfico, os usuários eram direcionados ao final do questionário.

A validação da compreensibilidade do questionário foi feita por meio de testes piloto com usuários de smartphone.

\begin{tabular}{|l|l|}
\hline Percepção de utilidade & Eu não sei o que eles são capazes de fazer \\
\hline Percepção de usabilidade & $\begin{array}{l}\text { Eles não têm capacidade para realizar as tarefas que eu } \\
\text { geralmente realizo }\end{array}$ \\
\hline & Eles demoram para realizar as tarefas que eu quero \\
\hline & Usar eles é difícil \\
\hline Eles não entendem meus pedidos \\
\hline Eles não reconhecem palavras em idiomas além do meu idioma de \\
\hline uso padrão
\end{tabular}

Quadro 1. Relação de variáveis e afirmações colocadas aos participantes, tendo como opção de resposta uma escala Likert de 5 pontos.

Todos os dados foram analisados no Excel 2017 (Microsoft, 2017). As perguntas de uso de assistentes de voz foram analisadas utilizando média. Já as escalas com os motivos para não usar os assistentes de voz foram analisadas quanto a tendência da amostra a um polo da escala. Por escalas Likert serem nominais, e, portanto, agrupadas e não intervalares, o método de análise escolhido foi a classe mediana (Crespo, 2009). Também foram feitos testes post hoc com teste $Z$ para avaliar se havia diferença significativa na porcentagem de concordância entre as afirmações. $O$ teste $Z$ foi feito utilizado um nível de significância alfa de 0.05. 


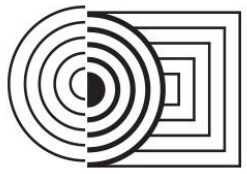

$17^{\circ}$ ERGODESIGN \& USIHC 2019

PUC-Rio, 11 a 13 de dezembro

Rio de Janeiro, RJ, Brasil $17^{\circ}$ Ergodesign - Congresso Internacional de Ergonomia e Usabilidade de Interfaces Humano Tecnológica: Produto, Informações Ambientes Construídos e Transporte

$17^{\circ}$ USIHC - Congresso Internacional de Ergonomia e Usabilidade de Interfaces Humano Computador

\section{RESULTADOS}

O questionário recebeu respostas entre os dias 27 de Maio e 04 de Junho de 2019. No total, foram recebidas 532 respostas, sendo que 522 concordaram em participar ou eram maior de 21 anos e 394 finalizaram o questionário. Os resultados do questionário consideraram todas as respostas válidas $(n=522)$, mesmo daqueles que não responderam até o final, já que, exceto pelas perguntas filtro (ex: Você usa assistentes de voz no seu smartphone?), nenhuma das perguntas era obrigatória. Assim, os resultados reportados a seguir podem ter número de respondentes $(n)$ diferente para cada pergunta. Como mencionado anteriormente, os resultados reportados neste artigo serão referentes apenas às respostas dos usuários que relataram não utilizar os assistentes de voz ou ter frequência de uso esporádica $(n=257)$.

\subsection{Uso de assistentes de voz}

As perguntas sobre uso de assistentes de voz tiveram como objetivo entender se os participantes que declararam não usar os assistentes de voz possuíam algum assistente em seu smartphone. A figura 1 mostra que $69 \%$ dos participantes afirmaram que têm um assistente de voz em algum dispositivo. Esse grupo de participantes seguiu para a próxima seção do questionário, sobre os motivos pelos quais não usam os assistentes de voz.

Foi possível observar, ainda, outros grupos de participantes derivados da pergunta sobre uso. Como ilustrado na figura 1,13\% dos respondentes afirmaram não ter assistentes em nenhum dispositivo, 7\% declararam não saber se têm um assistente e 11\% afirmaram que têm um assistente de voz, mas não sabe como ativá-lo. Esses grupos de participantes foram redirecionado à uma seção diferente, em que responderam à pergunta "Qual é o modelo do smartphone que você usa? (ex: Samsung Galaxy S8, iPhone 6 etc)".

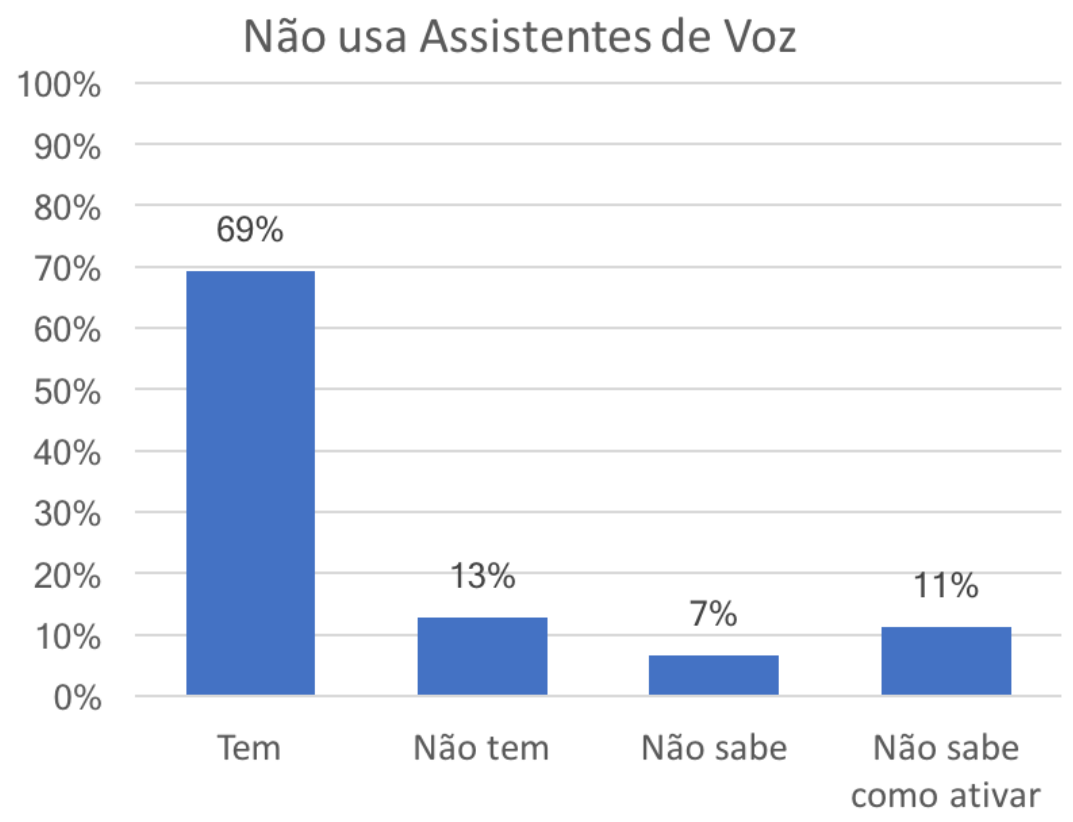

Figura 1. Porcentagem de respondentes que não usam assistentes de voz por uso. Pergunta: "Você tem um assistente de voz em algum dispositivo? (smartphone, relógio etc)". ( $n=257)$. 


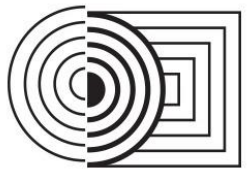

$17^{\circ}$ ERGODESIGN \& USIHC 2019

PUC-Rio, 11 a 13 de dezembro

Rio de Janeiro, RJ, Brasil $17^{\circ}$ Ergodesign - Congresso Internacional de Ergonomia e Usabilidade de Interfaces Humano Tecnológica: Produto, Informações Ambientes Construídos e Transporte

$17^{\circ}$ USIHC - Congresso Internacional de Ergonomia e Usabilidade de Interfaces Humano Computador

Analisando as respostas sobre o modelo do smartphone das pessoas que afirmaram não ter os assistentes de voz, é possível perceber algumas inconsistências. Dentre as respostas desses participantes, estão diversos modelos de iPhone (6, 7, 8 e, até mesmo, X) e alguns Samsung Galaxy (S8 e S9), que são modelos equipados com a Siri e o Google Assistente, respectivamente. Considerando esses resultados, é possível perceber que o desconhecimento sobre a existência do assistente de voz pode ser um motivo para não usá-lo. Além disso, observando a figura 1, fica evidente que uma porcentagem considerável (de 19\% a $31 \%$ ) das pessoas que não usam assistentes de voz não utilizam esses sistemas por não saberem se os têm, por não saberem como ativá-los ou, pior ainda, por acharem que não têm o assistente de voz. Isso mostra que uma porcentagem expressiva dos respondentes deixa de usar os assistentes de voz por causa do desconhecimento sobre a utilização do sistema.

\subsection{Motivos para não usar assistentes de voz}

Os respondentes que afirmaram ter assistentes de voz responderam à uma série de escalas para entender por quais motivos eles deixavam de usar os assistentes. Os usuários tenderam à neutralidade para as afirmações: "Eles só me entendem em lugares silenciosos"; "Eles demoram para realizar as tarefas que eu quero"; "Eles não reconhecem palavras em idiomas além do meu idioma de uso padrão"; "Eu me preocupo com o que será feito com os dados que eles recolhem sobre mim"; e "Eu não sei o que eles são capazes de fazer". As figuras 2 a 9 ilustram os resultados das análises de classe mediana que tenderam a um polo da escala, indicados pelo ícone vermelho nas imagens.

Os participantes que responderam à pergunta sobre desconforto em falar com uma máquina, associada à dimensão de atitude, tenderam a discordar que esse seja um motivo para deixarem de usar os assistentes de voz (figura 2). Outro motivo com o qual os respondentes tenderam a discordar foi a dificuldade de uso dos assistentes de voz, que está relacionada à dimensão de usabilidade (figura 3).

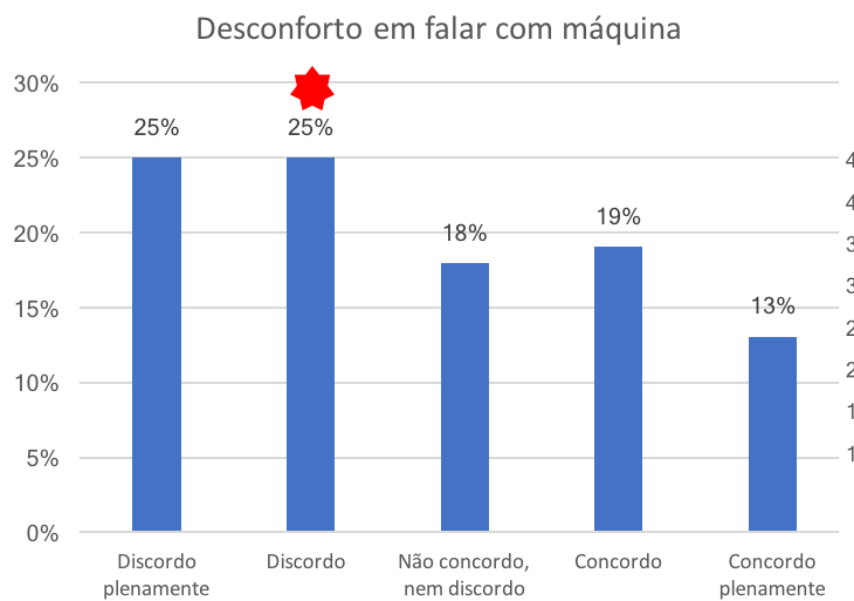

Figura 2. Tendência de concordância com a afirmação: "Eu deixo de usar os assistentes de voz porque: Eu me sinto desconfortável em falar com uma máquina". Classe mediana = discordo. $(n=184)$.

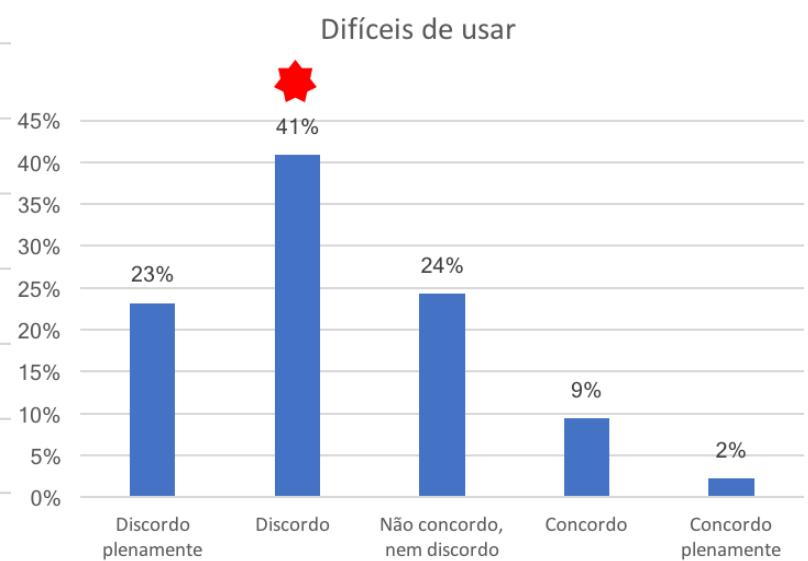

Figura 3. Tendência de concordância com a afirmação: "Eu deixo de usar os assistentes de voz porque: Usar eles é difícil". Classe mediana = discordo. $(n=181)$.

Dentre as afirmações com os quais os participantes tenderam a concordar como motivos para não usarem os assistentes de voz, está uma afirmação sobre modelo mental, que mostra 
$17^{\circ}$ ERGODESIGN \& USIHC 2019

PUC-Rio, 11 a 13 de dezembro Rio de Janeiro, RJ, Brasil $17^{\circ}$ Ergodesign - Congresso Internacional de Ergonomia e Usabilidade de Interfaces Humano Tecnológica: Produto, Informações Ambientes Construídos e Transporte

$17^{\circ}$ USIHC - Congresso Internacional de Ergonomia e Usabilidade de Interfaces Humano Computador

que os respondentes entendem que precisam usar palavras simples e falar de forma devagar e pontuada com os assistentes de voz (figura 4). Ainda, os participantes também apontaram um problema de usabilidade: a falha no reconhecimento dos comandos do usuário (figura 5).

Ter que falar de forma simples e pontuada

Não entendem os pedidos

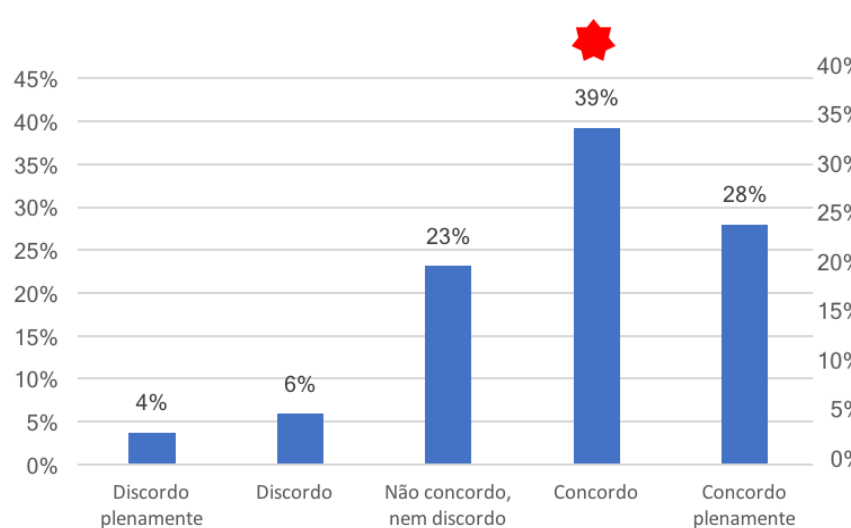

Figura 4. Tendência de concordância com a afirmação: "Eu deixo de usar os assistentes de voz porque: Eu tenho que usar palavras simples e falar de forma devagar e pontuada quando falo com eles". Classe mediana $=$ concordo. $(n=186)$.

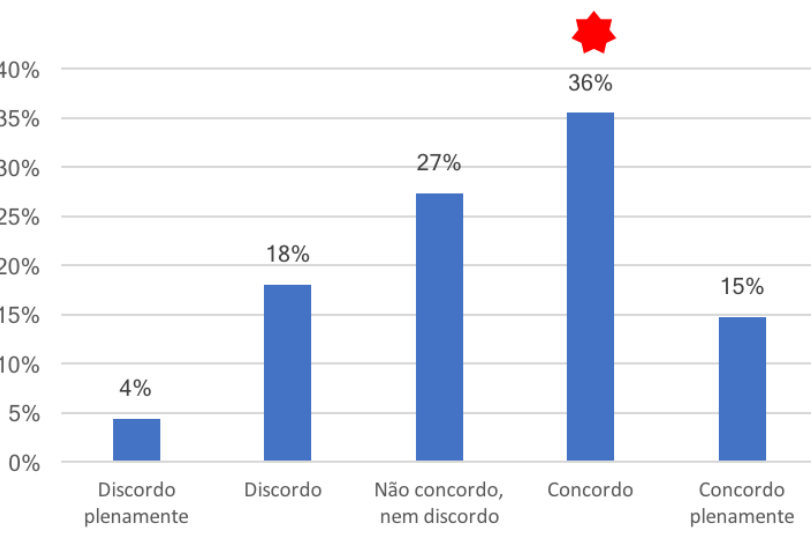

Figura 5. Tendência de concordância com a afirmação: "Eu deixo de usar os assistentes de voz porque: Eles não entendem meus pedido". Classe mediana $=$ concordo. $(n=183)$.

Além disso, os participantes também tenderam a concordar com alguns motivos relacionados à dimensão de atitude. Foram eles: o fato de outras pessoas poderem ouvir o que eles falam com os assistentes de voz (figura 6), o costume pela interface visual (figura 7), 0 esquecimento sobre os assistentes (figura 8) e a preguiça em usá-los (figura 9).

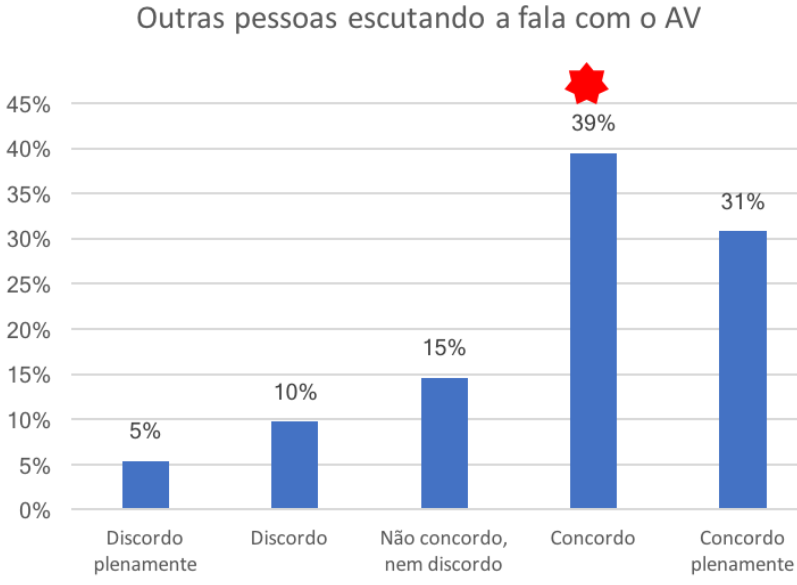

Figura 6. Tendência de concordância com a afirmação: "Eu deixo de usar os assistentes de voz porque: Não quero que outras pessoas ao meu redor escutem o que estou falando ou ouvindo". Classe mediana $=$ concordo. $(n=185)$.

\section{Costume com interface visual}

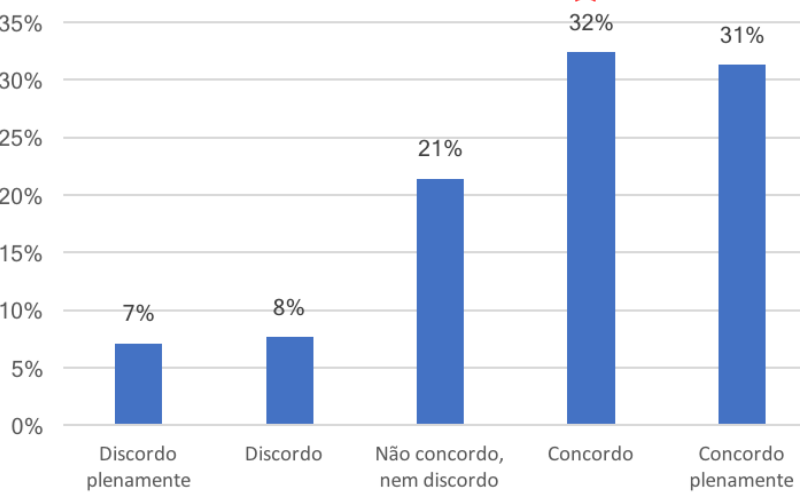

Figura 7. Tendência de concordância com a afirmação: "Eu deixo de usar os assistentes de voz porque: Eu estou acostumado(a) a usar a visão para interagir com meu dispositivo". Classe mediana = concordo. $(n=182)$. 
$17^{\circ}$ ERGODESIGN \& USIHC 2019

PUC-Rio, 11 a 13 de dezembro Rio de Janeiro, RJ, Brasil $17^{\circ}$ Ergodesign - Congresso Internacional de Ergonomia e Usabilidade de Interfaces Humano Tecnológica: Produto, Informações Ambientes Construídos e Transporte

$17^{\circ}$ USIHC - Congresso Internacional de Ergonomia e Usabilidade de Interfaces Humano Computador

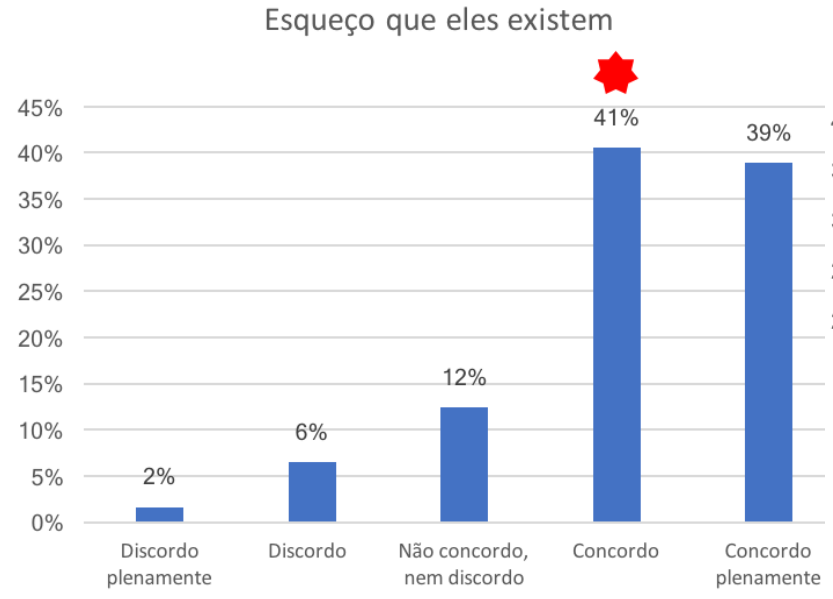

Figura 8. Tendência de concordância com a afirmação: "Eu deixo de usar os assistentes de voz porque: Eu esqueço que eles existem". Classe mediana $=$ concordo. $(n=185)$.
Tenho preguiça de usar

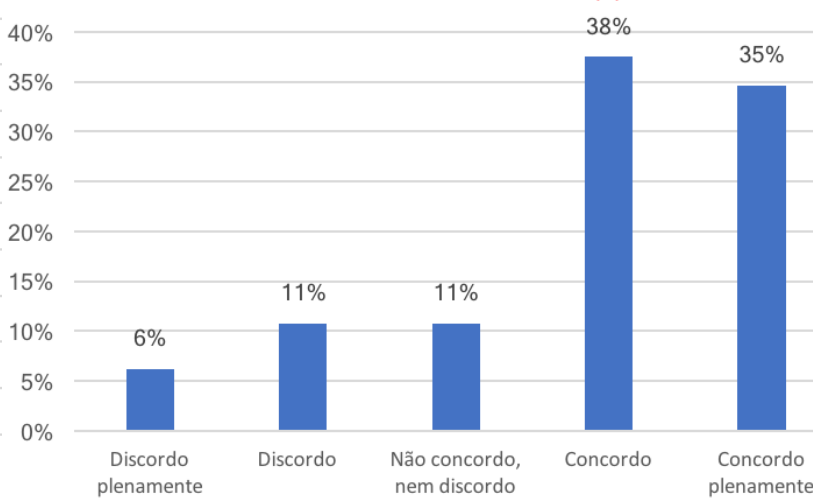

Figura 9. Tendência de concordância com a afirmação: "Eu deixo de usar os assistentes de voz porque: Eu tenho preguiça de usar eles". Classe mediana $=$ concordo. $(n=176)$.

Um teste de proporção $Z$ foi aplicado para verificar diferenças nas médias de participantes que tenderam a concordar com cada uma das afirmações que refletiram os motivos para não usar assistentes de voz. O teste apontou algumas diferenças significativas, ilustradas na figura 10.

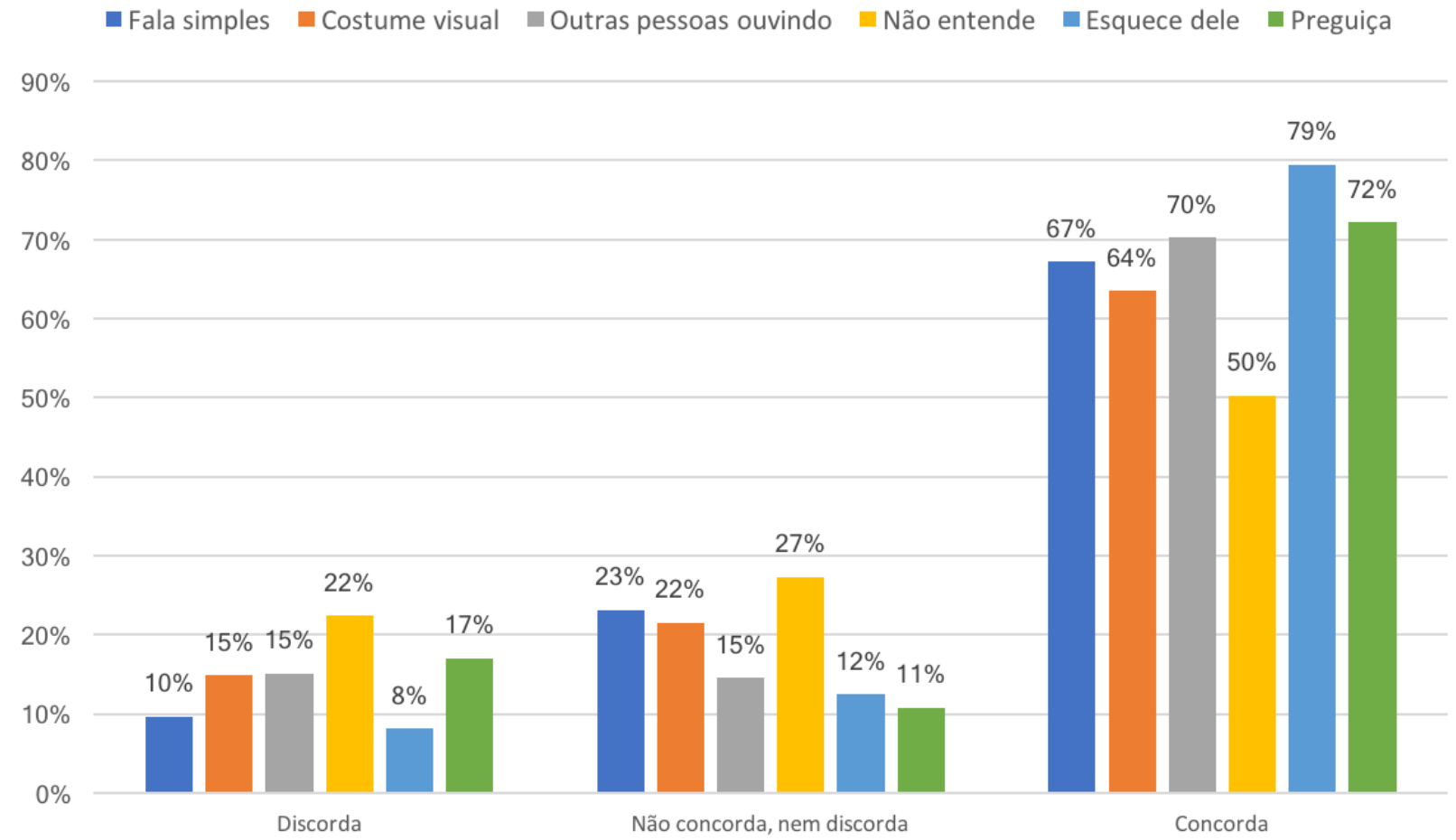

Figura 10. Comparação entre as médias de tendência aos polos das escalas para cada afirmação.

A barreira com a qual mais pessoas concordaram para deixarem de usar os assistentes de voz foi "Esqueço que eles existem", que foi significativamente maior do que todos as outras, 


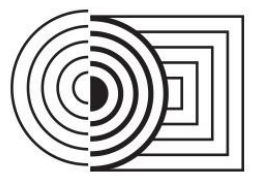

\section{$17^{\circ}$ ERGODESIGN \& USIHC 2019 \\ PUC-Rio, 11 a 13 de dezembro \\ Rio de Janeiro, RJ, Brasil}

$17^{\circ}$ Ergodesign - Congresso Internacional de Ergonomia e Usabilidade de Interfaces Humano Tecnológica: Produto, Informações Ambientes Construídos e Transporte

$17^{\circ}$ USIHC - Congresso Internacional de Ergonomia e Usabilidade de Interfaces Humano Computador

exceto pela "Preguiça" ( $Z=1.45, p=0.1)$. "Outras pessoas estarem ouvindo", "Costume pela interface visual" e "Ter que falar de forma simples" não tiveram diferença significativa entre si, mas foram significativamente maiores que "não entende meus pedidos" $(Z=4,325, p<0.001 ; Z$ $=2,996, p=0.01 ; Z=3,448, p=0.001)$, que foi significativamente menor do que todas as outras.

Os resultados sobre os motivos para não usar os assistentes de voz podem levar à algumas conclusões. Em primeiro lugar, a ausência de opinião para as escalas relativas à usabilidade, indica que problemas de usabilidade não são o motivo principal para as pessoas não usarem assistentes de voz. Essa possibilidade é reafirmada pelos resultados relativos à escala de "Eles não entendem meus pedidos", com a qual apenas $50 \%$ dos respondentes tenderam a concordar. Essa porcentagem, relativamente baixa, pode indicar que os usuários não experienciaram tantos problemas com reconhecimento dos comandos, possivelmente, porque não usam essas interfaces com frequência.

Adicionalmente, foi observado que os respondentes tenderam à neutralidade na escala que afirmava que os assistentes de voz só entendem comandos em lugares silenciosos, relacionada ao modelo mental de funcionamento. Assim como as questões relativas à usabilidade, isso pode apontar para a existência de uma relação entre uso e modelo mental de funcionamento sobre captação de comandos e barulho: Usuários de smartphone que não usam assistentes de voz não constroem um modelo mental sobre o local de funcionamento da interação por voz. De forma contrária, porém, os resultados do questionário apontaram para a existência de um modelo mental dos participantes em relação à forma como falam com os assistentes de voz.

Esses resultados mostram que mesmo os usuários de smartphone que não usam os assistentes de voz em sua rotina têm um modelo mental de funcionamento da interação por voz. Além disso, também é possível afirmar que esse modelo mental afeta a maneira com a qual os usuários falam com os assistentes de voz (levando-os a falar de forma clara, devagar e pontuada) e que isso é uma motivo pelo qual os usuários de smartphone deixam de usar os assistentes. É necessário investigar como esses usuários construíram essa percepção sobre a forma como devem falar com os assistentes.

De forma divergente da literatura (REUTERS INSTITUTE, 2018; COMSCORE, 2017b; MCLEAN e OSEI-FRIMPONG, 2019), a neutralidade em relação aos riscos de privacidade mostra que a preocupação com seus dados não parece ser uma barreira de uso de assistentes de voz para usuários brasileiros de smartphone. Além disso, a neutralidade em relação à afirmação "Eu não sei o que eles são capazes de fazer" reflete um possível desconhecimento das capacidades dos assistentes de voz por parte dos usuários de smartphone. Esse desconhecimento, relacionado à percepção de utilidade, é ruim, uma vez que é difícil perceber um produto como útil quando não se sabe para que ele serve e o que é capaz de fazer.

Finalmente, a tendência a concordar com algumas das escalas que refletiam a atitude em relação ao uso de assistentes de voz aponta para a possibilidade dessa dimensão ser o principal motivo pelo qual as pessoas não usam os assistentes de voz. Como é possível observar na figura 10, quatro dos motivos mais influentes para não utilizar essas interfaces são relativos à atitude: o esquecimento dos assistentes de voz, a preguiça em usá-los, o fato de outras pessoas poderem ouvir a interação e o costume com a interface visual.

\section{CONCLUSÃO}

Em um cenário de uso crescente de smartphones para as mais diversas tarefas, repensar as formas de interação humano-computador é fundamental. Considerando essa necessidade, os assistentes de voz se apresentam como uma alternativa à interface visual que 


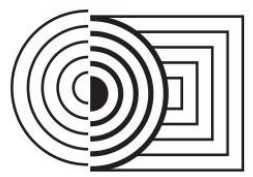

\section{$17^{\circ}$ ERGODESIGN \& USIHC 2019 \\ PUC-Rio, 11 a 13 de dezembro \\ Rio de Janeiro, RJ, Brasil}

$17^{\circ}$ Ergodesign - Congresso Internacional de Ergonomia e Usabilidade de Interfaces Humano Tecnológica: Produto, Informações Ambientes Construídos e Transporte

$17^{\circ}$ USIHC - Congresso Internacional de Ergonomia e Usabilidade de Interfaces Humano Computador

oferece diversos benefícios para a interação de usuários com smartphones. Apesar de suas vantagens, diversas questões ainda se apresentam como barreiras para o uso dos assistentes de voz. A literatura oferece alguns apontamentos sobre as principais questões no uso de assistentes de voz. No entanto, ainda são escassos os dados referentes ao uso de assistentes de voz por usuários no Brasil e, especificamente, no smartphone. Assim, esta pesquisa teve como objetivo avaliar se, e quais, características dos assistentes de voz impactam negativamente o uso desses sistemas por usuários brasileiros de smartphone, e a que nível isso acontece. Para isso, foi realizado um questionário online com esses usuários.

Os resultados do questionário mostraram que as principais barreiras no uso de assistentes de voz são as questões de atitude em relação ao uso dos assistentes. Questões como a preguiça em usar os assistentes, o esquecimento da existência desses sistemas, o costume pela interface visual e a preocupação com outras pessoas ouvindo a interação por voz foram as principais barreiras apontadas pelos usuários. Esses achados são similares aos resultados reportados na literatura (COMSCORE, 2017b; MAUÉS, 2019; REUTERS INSTITUTE, 2018), que apontaram que questões de atitude em relação ao uso de assistentes de voz impactam o uso desses sistemas. De forma contrária a literatura, porém, a preocupação com a privacidade de dados não foi apontada como uma barreira para o uso desses sistemas, o que pode ser uma especificidade do público brasileiro.

Além disso, pode-se observar que os problemas de usabilidade não se mostraram como grande barreira no uso dos assistentes de voz. Segundo Adell et al. (2014), apenas o uso real de um sistema revela os benefícios desse produto. Assim, é possível argumentar que, de forma similar, apenas o uso real e regular dos assistentes de voz pode mostrar seus problemas de usabilidade. No entanto, mesmo sem um uso regular dos assistentes de voz, foi possível observar que o modelo mental sobre a maneira de falar com os assistentes de voz impactou de forma negativa o uso desses sistemas. Considerando que os seres humanos se comunicam pela fala diariamente, a intuitividade da fala é uma das grandes vantagens das interfaces de voz (QUARESMA et al, 2018). Assim, a percepção sobre um "jeito correto" de falar com os assistentes de voz é negativa porque pode indicar a crença dos usuários que a interação pela fala com esses sistemas não é natural.

Ainda, os resultados do questionário mostraram que o desconhecimento de informações relativas ao funcionamento básico do assistente, bem como à suas capacidades, pode ser um motivo que leva os usuários de smartphone a não utilizar esses sistemas. Esses achados podem indicar que a forma como as informações sobre os assistentes estão sendo transmitidas para os usuários de smartphone não é transparente. De acordo com Saffer (2013), existem gatilhos que começam as interações, e, quanto mais importante é uma interação, mais visível é esse gatilho. No caso dos assistentes de voz, o gatilho é verbal (com expressões como "e aí Siri" ou "OK Google") ou por meio de um botão (geralmente, o botão inicial do smartphone). Assim, se, por um lado, ter o assistente a postos a um toque no botão inicial ou a um "E aí Siri" é bom, porque permite acessá-lo em qualquer tela do smartphone, por outro, pode significar que ela não está recebendo prioridade como interação.

Finalmente, é preciso ressaltar algumas limitações deste estudo. O questionário online, por sua natureza remota, tem como desvantagem a incapacidade de avaliar se o questionário foi respondido com sinceridade. Ainda, é importante ressaltar que o questionário foi respondido por usuários de smartphone brasileiros, no entanto, a amostra de respondentes não é representativa da população brasileira.

Os resultados desta pesquisa até o momento apontaram as principais barreiras no uso dos assistentes de voz. Considerando os achados reportados neste artigo, é necessário investigar mais profundamente por quê as questões relativas à atitude são uma grande barreira 


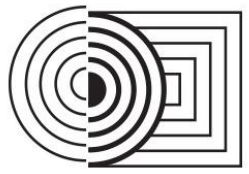

\section{$17^{\circ}$ ERGODESIGN \& USIHC 2019 \\ PUC-Rio, 11 a 13 de dezembro \\ Rio de Janeiro, RJ, Brasil}

$17^{\circ}$ Ergodesign - Congresso Internacional de Ergonomia e Usabilidade de Interfaces Humano Tecnológica: Produto, Informações Ambientes Construídos e Transporte

$17^{\circ}$ USIHC - Congresso Internacional de Ergonomia e Usabilidade

de Interfaces Humano Computador

para o uso de assistentes de voz, e quais são as maneiras de superá-las ao alcance do design. Uma possível maneira de fazer isso é entendendo se os usuários que utilizam os assistentes de voz atualmente já passaram por tais questões e como as superaram. Além disso, é necessário entender se a apresentação de informações sobre o assistente para os usuários é eficaz e se, realmente, está sendo uma barreira para o uso desses sistemas.

\section{REFERÊNCIAS BIBLIOGRÁFICAS}

ADELL. E., VÁRHELYI. A., NILSSON. L., The Definition of Acceptance and Acceptability. In:. REGAN, M. A., HORBERRY. T., STEVENS., A. (Eds.) Driver Acceptance of New Technology. Farnham: Ashgate, 2014.

AMAZON. What Is a Voice User Interface (VUI)? Disponível em: https://developer.amazon.com/pt-br/alexa-skills-kit/vui Acesso em 29 de Abril de 2019.

COMSCORE, Smart Speaker Penetration Hits 20\% of U.S. Wi-Fi Households. 2017a, Disponível em: https://www.comscore.com/por/Insights/Blog/Smart-Speaker-Penetration-Hits20-Percent-of-US-Wi-Fi-Households Acesso em 29 de Abril de 2019.

COMSCORE, Looking Ahead to the Voice Era. 2017b. Disponível em: https://www.comscore.com/por/Insights/Apresentacoes-e-documentos/2017/Looking-Ahead-tothe-Voice-Era Acesso em 29 de Abril de 2019.

CRESPO, A. A., Estatística fácil, 19 ed., São Paulo: Saraiva: 2009.

DAVIS, F. D., Perceived Usefulness, Perceived Ease of Use, and User Acceptance of Information Technology, In: MIS Quarterly, v.13-3, p.319-340, STOR, 1989.

EVAL\&GO, Eval\&Go, 2019. Disponível em: https://www.evalandgo.pt

GOOGLE. Consumer Barometer - Trending. 2017a. Disponível em: $<$ https://www.consumerbarometer.com/en/trending/?countryCode=BR\&category=TRNNOFILTER-ALL>. Acesso em 29 de Abril de 2019.

INVOCA, The rise of voice, 2018. Disponível em: https://go.invoca.com/ebook-Ip-therise-of-voice.html Acesso em 26 de Junho de 2019.

KLEINER PERKINS, 2016 Internet Trend Reports. 2016. Disponível em: https://www.kleinerperkins.com/perspectives/2016-internet-trends-report Acesso em 29 de Abril de 2019.

MAUÉS, M. P., Um olhar sobre os assistentes de voz personificados e a voz como interface, Dissertação (Mestrado em design), Departamento de Artes e Design, Pontifícia Universidade Católica do Rio de Janeiro, Rio de Janeiro, 2019.

MCLEAN, G., OSEI-FRIMPONG, K., Hey Alexa... Examine the variables influencing the use of Artificial Intelligent In-home voice assistant, In: Computer in Human Interaction, Manuscrito Aceito, Elsevier, 2019.

MICROSOFT, INC., Microsoft Excel (2017), 2017. Disponível em: https://www.microsoft.com/pt-br

MORIUCHI, E., Okay, Google!: An empirical study on voice assistants on consumer engagement and loyalty, In: Psychology and Marketing, 1-13, Willey, 2019. 


\section{$17^{\circ}$ ERGODESIGN}

\& USIHC 2019

PUC-Rio, 11 a 13 de dezembro

Rio de Janeiro, RJ, Brasil $17^{\circ}$ Ergodesign - Congresso Internacional de Ergonomia e Usabilidade de Interfaces Humano Tecnológica: Produto, Informações Ambientes Construídos e Transporte

$17^{\circ}$ USIHC - Congresso Internacional de Ergonomia e Usabilidade

de Interfaces Humano Computador

NASS, C., BRAVE, S., Wired for speech - How voice activates and advances Human-Computer relationship. Cambridge: The MIT Press, 2005.

NASS, C., MOON, Y., Machines and Mindlessness: Social Responses to Computers. In: Journal of Social Issues, v. 56, 81-103, Willey, 2000.

OSGOOD, C., SUCI, G. J., TANNENBAUM, P. H., The Measurement of Meaning, University of Illinois Press, 1957.

PEARL, C., Designing Voice User Interfaces: Principles of Conversational Experiences. O'Reilly, 2016. E-Book.

QUARESMA, M., MOTTA, I., ARAUJO, M., Revisão Bibliográfica de Diretrizes de Interação Sonora para Aplicativos de Smartphones, In: 13 Congresso Brasileiro de Pesquisa e Desenvolvimento em Design, 2018, Joinville. Anais do 13ํㅡㄹ Congresso Brasileiro de Pesquisa e Desenvolvimento em Design. Joinville: Univille, 2018. v. 1.

REUTERS INSTITUTE, The Future of Voice and the Implications for News. 2018. Disponível em: https://reutersinstitute.politics.ox.ac.uk/our-research/future-voice-andimplications-news Acesso em 29 de Abril de 2019.

SAFFER, D., Microinteractions - Designing with details, O'Reilly, Sebastopol, 2013.

WEST, M., KRAUT, R., CHEW, E. H., l'd blush if I can: Closing gender divides in digital skills through education, EQUALS Skills Coalition, 2019. Disponível em:

https://unesdoc.unesco.org/ark:/48223/pf0000367416 Acesso em 26 de Junho de 2019. 